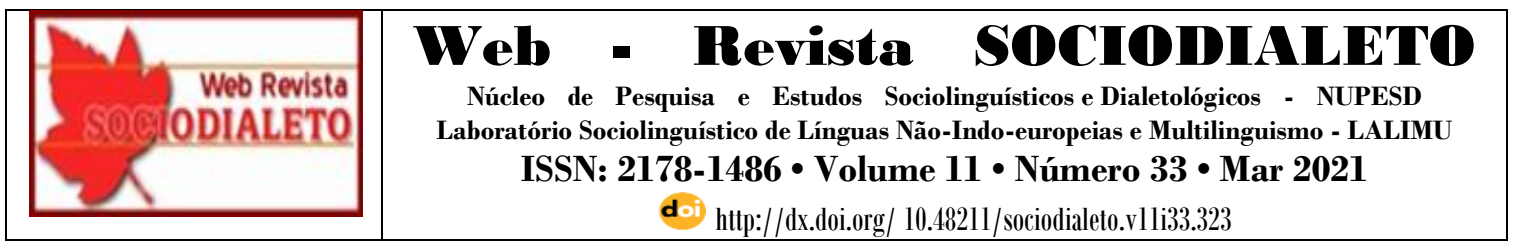

\title{
O INTÉRPRETE DE LIBRAS E A DIVERSIDADE LÍNGUISTICA DA CULTURA SURDA
}

\section{THE LIBRAS INTERPRETER AND THE LINGUISTIC DIVERSTYY OF THE DEAF CULTURE}

\author{
Luciene Nascimento Cardoso (PPGL/UNEMAT) ${ }^{1}$ \\ lucieneestudant@gmail.com
}

Taisir Mahmudo Karim (UNEMAT) ${ }^{2}$

taisirkarim@hotmail.com

\begin{abstract}
RESUMO: Considerando a importância que o professor e tradutor/intérprete de Língua Brasileira de Sinais (LIBRAS) como ouvinte tem nos processos de promoção e difusão da cultura surda, o objetivo deste trabalho é refletir sobre como este profissional poderia efetivamente concorrer para fomentar a inclusão de pessoas surdas em escolas regulares. Cumprindo a sua função social ao contribuir adequadamente com o pleno desenvolvimento cognitivo, político, social, emocional etc. do educando surdo. Também analisar os sentidos dos sinais ocorridos durante a comunicação na língua de sinais, respeitando as diversidades linguísticas presentes em cada espaço social. contribuindo para a possibilidade de proliferação da variação linguística sinalizada.
\end{abstract}

PALAVRAS-CHAVE: Cultura Surda; Educando Surdo; Diversidade Linguística; LIBRAS; Tradutor/Intérprete.

\begin{abstract}
Considering the importance that the teacher and translator/interpreter of Brazilian Sign Language (LIBRAS) as a listener has in the processes of promotion and dissemination of deaf culture, the aim of this paper is to reflect on how this professional could effectively compete to foster the inclusion of deaf people in regular schools. Fulfilling its social function by contributing appropriately to the full cognitive, political, social, emotional, etc. development of the deaf student. Also analyze the meanings of the signs occurring during communication in sign language, respecting the linguistic diversity present in each social space. contributing to the possibility of proliferation of sign language variation.
\end{abstract}

KEYWORDS: Deaf Culture; Educating the Deaf; Linguistic Diversity; LIBRAS; Translator/Interpreter.

\section{INTRODUÇÃO}

A presença de professores tradutor e intérprete de da Língua Brasileira de Sinais (Libras) é importante na articulação e mediação entre as duas culturas, a surda e a ouvinte,

\footnotetext{
${ }^{1}$ Mestranda em Linguística pela Universidade Estadual do Mato Grosso - UNEMAT e interprete de Língua Brasileira de Sinais no departamento de Letras - UNEMAT.

${ }^{2}$ Doutor em Linguística pela Universidade Estadual de Campinas - UNICAMP.
} 
fazendo a interpretação de uma língua para outra. Como alguns pesquisadores assim denomina, a exemplo de Bagno (2001), nas escolas regulares do Brasil atendem a uma demanda que historicamente teria sido reprimida, ou seja, muitos surdos foram privadas total ou parcialmente de ter acesso ao conhecimento formal produzidos pelo homem. Para superar esse grave problema sociedade brasileira, por diferentes meios, tem se mobilizado através de grupos e associações de surdos e de várias leis para tratar essa questão.

Em termos práticos, como apontam várias pesquisas, a exemplo de Lacerda (2006) e Silveira e Neves (2006), tem sido cada vez mais expressiva a presença de profissionais tradutor/intérprete de Libras para Língua Portuguesa Os benefícios são inúmeros, ao possibilitar que pessoas surdas, antes privadas total ou parcialmente de ter acessos aos saberes formais e aos valores morais disseminados pela escola, possam efetivamente de apropriar de outros saberes que são imprescindíveis para a vida em sociedade democráticas, como a brasileira através desse profissional que faz a interpretação português para Libras.

Mesmo acentuando-se uma série de problemas quanto à atuação do profissional tradutor/intérprete de Libra/Língua Portuguesa Brasileira, dado, entre outras coisas, as dificuldades e insuficiências nos processos formativos, seria relevante ressaltar o esforço que vem sendo feito na direção de superar tais problemas. Cleary (2005) destaca que a atuação do poder público em formalizar, mediante as leis, a atuação do profissional tradutor/intérprete de Libras/Língua Portuguesa tem contribuído para uma mudança de postura quanto a formação deste profissional, verificada em aspectos como: certificação, currículo, material didático e avaliação.

Conforme Ferreira-Brito (1997) e Quadros (1997), as línguas de sinais são línguas naturais, já que refletem a capacidade psicobiológica humana para a linguagem e surgiram da mesma forma que as línguas orais-auditivas.

É importante ressaltar, também, que as línguas de sinais não são subordinadas às línguas faladas e nem se originaram delas, mas, sim, a partir da necessidade natural de comunicação entre as pessoas surdas, pois percebemos que a necessidade de domínio nas duas línguas são fundamentais para atuação o professor intérprete de libras nos processos comunicativos de tradução. 
Segundo as autoras Quadros e Karnopp (2004) percebe-se que a língua portuguesa é uma língua utilizada através do canal oral auditivo, já a língua Brasileira de Sinais, faz uso de uma outra modalidade, ou espaço que pode ser chamado de espaço visual, podendo ser compreendido como canal visual, e a delimitação espacial pelo qual o falante sinaliza no espaço, assim o contexto interpretativo comunicativo auxilia através da construção da imagem gerando possibilidades lexicais. Segundo Eler (2017), foi Stokoe, um linguista americano que nos anos 60 ao analisar a forma de comunicação dos surdos fez a descoberta de que havia duas modalidades na língua, a oral auditiva e à espaço-visual, “[...] chegando à conceituação de modalidades linguísticas como oral auditiva e visual espacial, e que as línguas gestuais passavam pelos mesmos aspectos das línguas orais como o sintático, o semântico, o pragmático, o morfológico e o fonológico". (ELER, 2017. p. 40). Assim a partir dos estudos de Stokoe é que as línguas de sinais foram reconhecidas como língua que apresentam gramática própria com regras na organização do discurso em sinais e não mais como gestos aleatórios que os surdos faziam para se comunicar.

Pensando a variação linguística sinalizada pode-se dizer com base nos relatos dos sinalizantes, que é comum ouvir dizer que as pessoas surdas pensam através das cenas ou imagens que vão passando na mente como se fosse uma tela, podendo ser concebido como uma tecnologia, e são por esses meios que surgem a variação linguística na língua de sinais; a mudança e escolha lexicais podem ocorrer conforme a região, meio social em que o sujeito surdo esteja inserido. Levando cada grupo de surdos a sinalizarem ou fazer uso de um certo tipo de sinal, que constituem formas de sinalização diferentes, mas que possuem o mesmo significado.

Segundo Dias (2018) as formas de expressão são constituídas em unidades linguísticas na dimensão visual, também passível de estabelecer um paralelo com uma dimensão gráfica, logo podemos pensar que a visão dos surdos em conceber os significados das coisas através dos sinais seja um paralelo dessa dimensão. Corroborando com essa

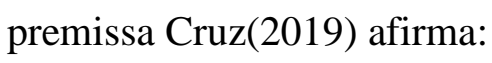

[...] entende-se que os signos da escrita precisam ser transformados em signos visuais com sentido para o Surdo, ou seja, os signos da escrita que têm conotação auditiva necessitam ser transferidos para a língua de sinais, 
que é visual e natural. Os signos também precisam ser interpretados na língua do Surdo, que por sua vez é uma língua significativa, pois é totalmente visual e, portanto, compreensiva. Não há como negar o fato de que a pessoa surda se apropria dos conhecimentos por meio da visão, das suas experiências visuais e não das experiências auditivas como ocorre com o sujeito ouvinte. (CRUZ, 2019, p. 76).

Pretendemos, pois, com este trabalho, sabendo que não se trata de algo abrangente devido a sua própria proposta, refletir sobre como este profissional intérprete e tradutor poderia efetivamente contribuir para fomentar a inclusão de pessoas surdas em escolas regulares, cumprindo a sua função social ao contribuir proficuamente com os processos de desenvolvimento cognitivo, político, social, emocional do educando surdo. Tomamos como referência para tal reflexão que, entre outros fatores, a promoção da cultura surda é fundamental para que tais objetivos sejam alcançados. Isto significa ressaltar a importância da mediação do tradutor/intérprete de Libras/Língua Portuguesa nos processos que relacionam a cultura surda e a cultura ouvinte.

\section{A FUNÇÃO SOCIAL DO INTÉRPRETE/TRADUTOR DE LIBRAS}

Em diversas pesquisas realizadas e publicadas ultimamente, a exemplo de Lacerda (2006) e Silveira e Neves (2006), tem citado a presença do tradutor e intérprete de Libras/ Língua Portuguesa em escolas regulares e as problemática a eles atribuídas. Esta realidade tem sido possível desde que o Brasil se tornou signatário da Conferência de Jomtien, Tailândia realizada em 1990 e que resultou em uma Declaração Mundial sobre Educação Para Todos e com as políticas de inclusão no Brasil tem garantido o direito aos surdos ao acesso ao conhecimento através da tradução e interpretação do ambiente de sala de aula. Neste documento já se visualiza a necessidade da escola regular se tornar efetivamente inclusiva, recebendo educandos com deficiência, entre eles o surdo.

A Conferência Mundial sobre Necessidades Educativas Especiais: Acesso e Qualidade realizada em Salamanca na Espanha em 1994 especificou os princípios de 
atendimento as pessoas com deficiência nas escolas, com destaque para a importância que isto ocorra em escolas regulares. Entre as suas sugestões estão: 1) o princípio que indica que a escola deve adaptar-se às especificidades dos educandos, e não os educandos as especificidades da escola; 2) que o ensino deve ser diversificado e realizado num espaço comum a todas as crianças. (ARRIENS, 2006).

Partimos do pressuposto que a adaptação tanto da escola quanto em outras instituições para o aluno surdo, estão baseadas no Decreto Federal 5.626 de 2005, que regulamentou a Lei de Libras e o artigo 18 da Lei $n^{\circ} 10.098$ de dezembro de 2000, que orienta a possibilidade e acessibilidade de comunicação nesses espaços.

Estas orientações levaram à implementação de importantes leis que dão suporte e reconhecem a atuação do profissional tradutor intérprete de Libras/Língua Portuguesa. A Lei Federal n 10.436 de 24 de abril de 2002, reconhece a existência da Língua Brasileira de Sinais (LIBRAS) como língua materna de pessoas surdas e ainda prevê a formação do profissional tradutor/intérprete de Libras. O Decreto $\mathrm{n}^{0} 5.626$ de 22 de dezembro de 2005 , por sua vez, tornou obrigatória a presença do profissional tradutor intérprete de Libras/ Língua Portuguesa nas escolas que recebem os alunos surdos. A Lei Federal n ${ }^{\circ} 12.319$ de $1^{\circ}$ de setembro de 2010 , avança significativamente ao reconhecer a profissão de tradutor intérprete de Libras/Língua Portuguesa.

Além destas orientações que ocorrem em nível de políticas públicas para o surdo, pode-se ainda destacar o aumento expressivo da demanda por parte das famílias de pessoas surdas para que elas possam ser mais bem atendidas quanto ao direito à educação. Os dados, em relação ao Brasil ainda seriam muito dispersos, mas algumas pesquisas, a exemplo da mostrada por Milanês e Poker (2015), revelam uma maior preocupação da sociedade com as pessoas surdas, o que tem aumentado a sua presença em escolas, principalmente as regulares.

Estas leis, bem como um maior interesse manifesto da sociedade pela questão, e os estudos na área da surdez têm sido fundamentais para a promoção da educação bilíngue, ou seja, da interação entre a cultura surda a cultura ouvinte. Por esta perspectiva, a Língua Brasileira de Sinais (LIBRAS) é reconhecida como a primeira língua da pessoa surda, ou 
seja, sua língua natural e a língua oficial do país, no caso, a Língua Portuguesa Brasileira, passa a ser aceita como a sua segunda. Segundo Eler (2017): “[...] o uso das duas línguas em questão, a língua de sinais e o português somente na sua forma escrita, deixando de lado a parte oral da língua". (ELER, 2017, p. 39). Tal condição, refletida por Goldfeld (1997), é determinante para o desenvolvimento identitário da pessoa surda, ao possibilitar o seu desenvolvimento não apenas no universo da comunidade surda, mas também na interação com a comunidade ouvinte.

Considerando este cenário, pode-se argumentar a relevância que o intérprete educacional tem no espaço escolar nos processos que possibilitam o desenvolvimento da pessoa surda. A mediação entre cultura surda e cultura ouvinte ganha novos contornos na perspectiva de sua contribuição para a consubstanciação da identidades e cultura da pessoa surda.

[...] os espaços educativos têm como função a preservação e a transmissão cultural e, para isso, é essencial que seja um espaço acessível para todas as pessoas, independentemente de suas potencialidades ou diferenças. Ao se abordar a educação da pessoa surda, é essencial que se conheça como ela vem acontecendo atualmente, quais as ferramentas e adaptações utilizadas e, especialmente, os personagens que integram nesse cenário, no caso o intérprete educacional seria o protagonista porque é ele que detém as competências e habilidades de transmitir o conhecimento da língua portuguesa para a língua de sinais. (CRUZ, 2019, p. 88).

Neste caso, visualiza-se a importância do papel social deste profissional, que se realiza adequadamente ao contribuir de forma substancial em tais processos de interação e aprendizagem. Ressalta-se ainda, que a atuação de tal profissional não sobrepõe à autonomia da pessoa surda, pois os processos de apreensão e significação da realidade, como destacado por Vygotsky (1996), ocorrem individualmente.

Sobre tal perspectiva, Vygotsky (1987) enfatiza que a interação, ou seja, no meio social que a criança vive é que se estabelece as primeiras relações com a realidade, e isto acontece por meio da linguagem. Desse modo, a linguagem significa a mediação simbólica entre o sujeito e o mundo. O pensamento e fala se unem e dão sentido a realidade. Este processo dinamiza-se pela fala social, num primeiro instante, em seguida pela fala 
egocêntrica, quando o sujeito toma para a determinação na sociedade, até atingir a fala interior, que resulta do pensamento reflexivo.

Portanto, o processos de interação social, se torna um lugar profícuo para a atuação do profissional tradutor intérprete de Libras/Língua Portuguesa Brasileira, considerando a importância que as dinâmicas de interação entre a cultura surda e a cultura ouvinte têm para o desenvolvimento desses indivíduos.

Arriens (2006) destaca alguns aspectos que seriam fundamentais no ato de interpretar/traduzir: (1) a escolha conceitual deve ser pautada muito mais pelas intenções do que as palavras em si, proporcionando a busca por uma equivalência dos significados de uma língua para a outra, um retrato da organização processual, condição que iria para além da intenção semântica; (2) a necessidade de a tradução ocorrer no discurso direto. Neste caso, o objetivo é possibilitar maior fidelidade ao que está sendo enunciado pelo locutor e evitar os problemas oriundos do discurso indireto, condição que remete a transformação da tradução num espaço de enunciação; (3) outro aspecto significativo é o contato visual do tradutor/enunciador com receptor surdo. Isto resulta não apenas no estabelecimento de vínculo e cumplicidade entre ambos, mas também permite lidar diretamente com a dinâmica da comunicação que, inclusive, vai além do previsto e do formal, representando sentimentos em cada ato da comunicação; entre outros.

Tomando estas referências como possibilidade de se refletir sobre a importância social do tradutor intérprete de Libras/Língua Portuguesa Brasileira nos processos de realização do bilinguismo, pode-se sugerir que este profissional, além de outras habilidades e competências, realize a sua função social mediante o atendimento daquilo que prevê a legislação brasileira e das demandas da sociedade nesta direção, bem como ao tomar como referência suas práticas de respeito aos princípios da cidadania e da democracia, considerando ainda que a sociedade brasileira resulta de um caldeamento de origens étnicoculturais diversas, condição determinante dos arranjos sociais e dos modos de vida que caracterizam a sociedade brasileira.

Dito de outro modo, a observância de tais elementos na prática do intérprete educacional contribui sobremaneira para fomentar os processos de interatividade entre as 
pessoas surdas e o universo dos ouvintes, e vice-versa. Desta forma, pressupõe-se que nestes processos interativos, mediados, no ambiente escolar, por este profissional dinamize-se não apenas a cultura surda, substrato na formação identitária de educandos surdos, mas que a interação com a cultura ouvinte também se dê de forma a contribuir nos processos de formação sócio-político-cultural destes sujeitos.

\section{CONSIDERAÇÕES FINAIS}

Como se pretendeu discutir nesta pesquisa, o papel a ser desempenhado pelo tradutor e intérprete da Língua Brasileira de Sinais/Língua Portuguesa Brasileira iria para muito além daquilo que é previsto pela legislação brasileira em consonância com documentos internacionais que orientam as políticas públicas voltadas para pessoas surdas, e que o Brasil é signatário. Pode-se argumentar que a função social deste profissional se realiza, enfim, ao contribuir proficuamente para que o educando surdo possa ter acesso as dimensões superiores do conhecimento formal e moral que possam efetivamente serem úteis em seus processos de desenvolvimento cognitivo, político, social, artístico e cultural.

Assim, percebe-se que para atentarmos ao papel social do intérprete de Libras, é necessário aprofundar aos estudos de variação linguística em Língua Brasileira de sinais.

A promoção da cultura surda, neste caso específico, seria condição sine qua non para fomentar a construção identitária de pessoas surdas. Nestes processos, o tradutor e intérprete de Libras/Língua Portuguesa Brasileira teria um papel central. Por meio de sua atuação poderia ocorrer a desejada interação entre a cultura surda e a cultura ouvinte, em bases que respeitariam os princípios da democracia, sustentada pelo respeito aos valores cidadão e a diversidade como condição de formação do surdo participante da sociedade brasileira.

\section{REFERÊNCIAS}

ARRIENS, Marco Antônio. A questão da tradução da LIBRAS para o Português. Fórum, vol. 13, jan/jun 2006, Rio de Janeiro: Instituto Nacional de Educação de Surdos. 


\begin{tabular}{|c|c|}
\hline $\begin{array}{r}\text { Web Revista } \\
\text { ODIALETO }\end{array}$ & $\begin{array}{c}\text { Núcleo de Pesquisa e Estudos Sociolinguísticos e Dialetológicos - NUPESD } \\
\text { Laboratório Sociolinguístico de Línguas Não-Indo-europeias e Multilinguismo - LALIMU } \\
\text { ISSN: 2178-1486 • Volume 11 • Número 33 • Mar 2021 } \\
\text { doi http://dx.doi.org/ } 10.48211 \text { /sociodialeto.vlli33.323 }\end{array}$ \\
\hline
\end{tabular}

Disponível em: <http://www.ines.gov.br/wp-content/uploads/2014/04/forum_131.pdf>. Acesso em 1 julho. 2020.

BAGNO, Marcos. Português ou Brasileiro? Um convite à pesquisa. São Paulo: Parábola Editorial, 2001.

BRASIL. Constituição da República Federativa do Brasil (1988). 40 ed. São Paulo: Saraiva, 2007.

BRASIL. Decreto Federal n 5.626 de 22 de dezembro de 2005. Regulamenta a Lei no 10.436, de 24 de abril de 2002, que dispõe sobre a Língua Brasileira de Sinais - Libras, e o art. 18 da Lei no 10.098, de 19 de dezembro de 2000. Disponível em: <http://www.planalto.gov.br/ccivil_03/_ato2004-2006/2005/decreto/d5626.htm>. Acesso em: 10 julho de 2020.

BRASIL. Estatuto da Criança e do Adolescente. 15 ed. São Paulo: Saraiva, 2007.

BRASIL. Lei no 9.394 de 20 de dezembro de 1996 (1996). Estabelece as diretrizes e bases da educação nacional. Disponível em <http://www.planalto.gov.br/ccivil/LEIS/L9394.htm>. Acesso em: 7 de julho de 2020.

BRASIL. Lei $\mathbf{n}^{\mathbf{0}} \mathbf{1 0 . 4 3 6}$, de 24 de abril de 2002. Dispõe sobre a língua brasileira de sinais - Libras e dá outras providências. Disponível em: <http://www.planalto.gov.br/ccivil_03/LEIS/2002/L10436.htm>. Acesso em: jul. 2020.

BRASIL. Lei $\mathbf{n}^{\mathbf{0}}$ 12.319, de 1 de setembro de 2010. Regulamenta a profissão de tradutor e intérprete da língua brasileira de sinais (LIBRAS). Disponível em:

<http://www.planalto.gov.br/ccivil_03/_Ato2007-2010/2010/Lei/L12319.htm>. Acesso em: jul. 2020.

BRASIL. Ministério da Educação e Cultura. Parâmetros Curriculares Nacionais: Adaptações Curriculares, Estratégias para a Educação de Alunos com necessidades Educacionais Especiais. Brasília: MEC/SEE, 1999.

CRUZ, J, Silva. O INTÉRPRETE DE LÍNGUA DE SINAIS NA EDUCAÇÃo SUPERIOR: LIMITES E POSSIBILIDADES. Dissertação do Mestrado em Letras da Universidade Federal de Rondônia - Porto Velho/RO: 2019.

DIAS, Luiz Francisco. Enunciação e Relações Linguísticas, Campinas, SP: Pontes Editores, 2018.

ELER, R. R. de Souza. Mapeamento de sinais da educação escolar indígena dos surdos Paiter Suruí. Dissertação do Mestrado em Letras da Universidade Federal de Rondônia Porto Velho/RO: 2017.

FERREIRA BRITO, Lucinda. Integração social \& educação de surdos. Rio de Janeiro, RJ: Babel, 1993.

GOLDFELD, M. A criança surda. São Paulo, SP: Pexus, 1997.

LABOV, Willhiam. A estratificação social do inglês falado em nova Iorque. Washington: D.C. Centro de Aplicação Linguística, 1996. 


\begin{tabular}{|c|c|}
\hline $\begin{array}{r}\text { Web Revista } \\
\text { SO.GLDIALETO }\end{array}$ & $\begin{array}{c}\text { Núcleo de Pesquisa e Estudos Sociolinguísticos e Dialetológicos - NUPESD } \\
\text { Laboratório Sociolinguístico de Línguas Não-Indo-europeias e Multilinguismo - LALIMU } \\
\text { ISSN: 2178-1486 • Volume } 11 \bullet \text { Número 33・ Mar 2021 } \\
\text { doi http://dx.doi.org/ } 10.48211 / \text { sociodialeto.vlli33.323 }\end{array}$ \\
\hline
\end{tabular}

LACERDA, Cristina Broglia Feitosa de: A inclusão escolar de alunos surdos: o que dizem alunos, professores e intérpretes sobre esta experiência (2006). Disponível em: <http://www.scielo.br/pdf/\%0D/ccedes/v26n69/a04v2669.pdf> Acesso em: 19 julho 2020.

MILANEZ, Simone Ghedini Costa e POKER, Rosimar Bortolini. Mapeamento da situação educacional dos alunos surdos de municípios brasileiros atendidos pelo curso de Língua Brasileira de Sinais na modalidade à distância (2015). Disponível em: $<$ http://seer.fclar.unesp.br/iberoamericana/article/viewFile/3487/3258>. Acesso em: 2 julho 2020 .

QUADROS, Ronice Muller de; KARNOPP, Lodenir Becker. Língua de Sinais Brasileira: estudos linguísticos. Porto Alegre: Artmed, 2004.

SILVEIRA, Flávia Furtado e NEVES, Marisa Maria Brito da Justa: Inclusão Escolar de Crianças com Deficiência Múltipla: Concepções de Pais e Professores (2006). Disponível em: <http://www.scielo.br/pdf/\%0D/ptp/v22n1/29847.pdf> Acesso em: 19 julho. 2020.

VYGOTSKY, Lev S. Pensamento e linguagem. São Paulo: Martins Fontes, 1987.

VYGOTSKY, Lev S. A formação social da mente. Rio de Janeiro: Martins Fontes, 1996.

Recebido em: 20/08/2021 | Aprovado em: 16/10/2020. 